\title{
Liquid-Liquid Equilibria of UCON + (Sodium or Potassium) Phosphate Salt Aqueous Two-Phase Systems at $23{ }^{\circ} \mathrm{C}$
}

\author{
Sara C. Silvério, ${ }^{\dagger, \ddagger}$ Oscar Rodríguez, ${ }^{\dagger}$ José A. Teixeira, and Eugénia A. Macedo ${ }^{*}, \dagger$ \\ LSRE-Laboratory of Separation and Reaction Engineering, Associate Laboratory LSRE/LCM, Department of Chemical \\ Engineering, Faculty of Engineering, University of Porto, Rua Dr Roberto Frias s/n, 4200-465 Porto, Portugal, and IBB-Institute \\ for Biotechnology and Bioengineering, Centre for Biological Engineering, Universidade do Minho, Campus de Gualtar, \\ 4710-057, Braga, Portugal
}

\begin{abstract}
Six phase diagrams for UCON-phosphate salt aqueous two-phase systems (ATPSs), at $23^{\circ} \mathrm{C}$, are presented. The ATPSs were obtained combining UCON (a random copolymer of $50 \%$ ethylene oxide and $50 \%$ propylene oxide) and a phosphate salt $\left(\mathrm{KH}_{2} \mathrm{PO}_{4}, \mathrm{~K}_{2} \mathrm{HPO}_{4}\right.$, potassium phosphate buffer $\mathrm{pH}=7, \mathrm{NaH}_{2} \mathrm{PO}_{4}$, $\mathrm{Na}_{2} \mathrm{HPO}_{4}$, and sodium phosphate buffer $\mathrm{pH}=7$ ). Among the salts used, $\mathrm{Na}_{2} \mathrm{HPO}_{4}$ proved to be the most effective in ATPS formation, providing the greatest heterogeneous region in the phase diagram. The previous established relation between the anion valence and the concentration needed to form a biphasic system was confirmed: higher valence requires lower concentration. $\mathrm{Na}^{+}$salts require, in all cases, lower concentration to form ATPSs than the corresponding $\mathrm{K}^{+}$salts. The size of the heterogeneous region in the phase diagrams increases with an increase of the $\mathrm{pH}$ value of the salt used in ATPS preparation.
\end{abstract}

\section{Introduction}

Aqueous two-phase systems (ATPSs) are biphasic systems composed mainly of water $(>80 \%)$. The aqueous phase splitting may happen when two aqueous solutions of different constituents (usually two polymers or a polymer and a salt) are mixed above some critical conditions (temperature and concentration). ATPSs have been widely used in biotechnology for the extraction and recovery of several types of biological solutes, like virus, ${ }^{1}$ cells, ${ }^{2}$ or proteins. ${ }^{1,3}$ Mild conditions, easiness to scale-up, robustness, and the possibility of direct application to fermentation broths are some of the main characteristics that contribute to the success of this technique. At the industrial level, polymer-saltATPSscan offersomeadvantagesoverpolymer-polymer ATPSs, namely, lower costs and viscosities (which provides mass-transfer limitations). Polymers are generally more expensive than salts, and for this reason polymer recycling receives particular attention. The use of stimuli responsive polymers (also called smart polymers) can make the recycling process easier. These kinds of polymers are able to respond, with significant property changes, to small changes in the surrounding environment. ${ }^{4}$ There are many different stimuli polymers can respond to, such as temperature, $\mathrm{pH}$, light, or ionic strength. High polymer recovery has been reported for ATPSs formed by light-sensitive ${ }^{5,6}$ and temperature-sensitive polymers. ${ }^{7,8}$ The polymer used in this work, UCON, is an example of a temperature-responsive (or thermoseparating) polymer. When heated above the critical temperature (about $50{ }^{\circ} \mathrm{C}^{7,9}$ ), UCON separates from the aqueous solution, thus facilitating polymer recovery and reutilization.

In this work, the binodal curves and three tie-lines were obtained experimentally for six UCON-phosphate salt ATPSs at $23{ }^{\circ} \mathrm{C}$. The phosphate salts used $\left(\mathrm{KH}_{2} \mathrm{PO}_{4}, \mathrm{~K}_{2} \mathrm{HPO}_{4}\right.$,

* Corresponding author. Phone: +351 22508 1653. Fax: +351 22508 1674. E-mail: eamacedo@fe.up.pt.

University of Porto.

$\doteqdot$ Universidade do Minho. potassium phosphate buffer $\mathrm{pH}=7, \mathrm{NaH}_{2} \mathrm{PO}_{4}, \mathrm{Na}_{2} \mathrm{HPO}_{4}$, and sodium phosphate buffer $\mathrm{pH}=7$ ) allow a study of the effects of both cations and anions in the size of the heterogeneous region and in the slope of the tie-lines.

\section{Experimental Section}

Materials. UCON 50-HB-5100, a random copolymer (average molecular weight $\mathrm{Mr}=3900$ ) of $50 \%$ ethylene oxide and 50 $\%$ propylene oxide, was obtained from Union Carbide (NY, USA). Potassium dihydrogen phosphate $\left(\mathrm{KH}_{2} \mathrm{PO}_{4}\right)$ was provided by USB Corporation (anhydrous, $\geq 99.9 \%$ ), and dipotassium hydrogen phosphate $\left(\mathrm{K}_{2} \mathrm{HPO}_{4}\right)$ (anhydrous, $99.99 \%$ Suprapur), sodium dihydrogen phosphate dihydrate $\left(\mathrm{NaH}_{2} \mathrm{PO}_{4} \cdot 2 \mathrm{H}_{2} \mathrm{O}\right)$ (p.a., Reag. Ph Eur), and disodium hydrogen phosphate $\left(\mathrm{Na}_{2} \mathrm{HPO}_{4}\right)$ (anhydrous, GR for analysis, ACS, Reag. Ph Eur) were supplied by Merck. All products were used as received without further purification. Stock solutions of each chemical were prepared in deionized water (ca. $50 \%$ by weight for UCON, $15.5 \%$ by weight for $\mathrm{KH}_{2} \mathrm{PO}_{4}, 20 \%$ by weight for $\mathrm{K}_{2} \mathrm{HPO}_{4}, 20 \%$ by weight for $\mathrm{NaH}_{2} \mathrm{PO}_{4}$, and $13 \%$ by weight for $\mathrm{Na}_{2} \mathrm{HPO}_{4}$ ), and all concentrations were obtained gravimetrically after evaporation on a heating plate (Stuart hot plate SB300) for salts or after lyophilization (Scan Vac, model CoolSafe 55-4) for UCON. Potassium phosphate buffer $(1 \mathrm{M}, \mathrm{pH}=7)$ was obtained by combining the $\mathrm{KH}_{2} \mathrm{PO}_{4}$ and $\mathrm{K}_{2} \mathrm{HPO}_{4}$ salts. Sodium phosphate buffer $(1 \mathrm{M}, \mathrm{pH}=7)$ was prepared combining the $\mathrm{NaH}_{2} \mathrm{PO}_{4}$ and $\mathrm{Na}_{2} \mathrm{HPO}_{4}$ salts. Buffer concentrations $(14.3 \%$ by weight for potassium phosphate buffer and $13.2 \%$ by weight for sodium phosphate buffer) were obtained gravimetrically after evaporation on a heating plate. The $\mathrm{pH}$ value was confirmed using a pH meter (VWR, SimpHony SB70P). Deionized water was used for all diluting purposes. All weighing was carried out on an Adam Equipment balance model AAA250L, precise to within $\pm 0.2 \mathrm{mg}$.

Methods. The binodal curves were obtained experimentally using the cloud-point method. Different biphasic systems, with known polymer and salt compositions, were prepared by weight 
Table 1. Parameters $a, b$, and $c$ and the Coefficient of Determination $\left(r^{2}\right)$ Obtained for the Six Systems Using Equation 1 Proposed by Merchuk and Co-workers ${ }^{10}$

\begin{tabular}{lcccc}
\hline \multicolumn{1}{c}{ system } & $a$ & $b$ & $c$ & $r^{2}$ \\
\hline $\mathrm{UCON}-\mathrm{K}_{2} \mathrm{HPO}_{4}$ & $0.949 \pm 0.019$ & $-7.740 \pm 0.191$ & $6104 \pm 270$ & 0.9995 \\
$\mathrm{UCON}-\mathrm{KPB}^{a}$ & $0.991 \pm 0.031$ & $-7.837 \pm 0.249$ & $3584 \pm 229$ & 0.9993 \\
$\mathrm{UCON}-\mathrm{KH}_{2} \mathrm{PO}_{4}$ & $1.021 \pm 0.036$ & $-5.967 \pm 0.224$ & $909 \pm 80$ & 0.9995 \\
$\mathrm{UCON}-\mathrm{Na}_{2} \mathrm{HPO}_{4}$ & $0.950 \pm 0.021$ & $-9.502 \pm 0.211$ & $7939 \pm 529$ & 0.9991 \\
$\mathrm{UCON}-\mathrm{NaPB}^{b}$ & $0.888 \pm 0.022$ & $-8.171 \pm 0.240$ & $3011 \pm 74$ & 0.9991 \\
$\mathrm{UCON}-\mathrm{NaH}_{2} \mathrm{PO}_{4}$ & $0.882 \pm 0.016$ & $-5.671 \pm 0.132$ & 0.9991
\end{tabular}

${ }^{a}$ KPB: Potassium phosphate buffer. ${ }^{b} \mathrm{NaPB}$ : Sodium phosphate buffer.

in assay tubes. The tubes were vigorously shaken in a vortex mixer (VWR, model VV3) and placed into a thermostatic bath (Techne, Tempette TE-8D) at $(23 \pm 0.2){ }^{\circ} \mathrm{C}$. Known amounts of water were successively added to the tubes until one homogeneous phase was obtained. After each addition of water, the tubes were shaken and placed back into the thermostatic bath for phase separation. The binodal curves were determined for the several compositions corresponding to the homogeneous system formation. Each experimental binodal curve was adjusted to the empirical equation suggested by Merchuk and coworkers ${ }^{10}$

$$
Y=a \cdot \exp \left(b \cdot X^{0.5}-c \cdot X^{3}\right)
$$

where $Y$ and $X$ are the polymer and salt compositions in mass fraction, respectively, and $a, b$, and $c$ are adjustable parameters. These parameters were obtained by nonlinear regression (leastsquares) using the SigmaPlot v5.0 (SPSS Inc.) software.

Three different tie-lines were determined for each UCON-salt system. Biphasic systems with known composition of UCON and salt (total weight of $20 \mathrm{~g}$ ) were prepared by weight in separating funnels, vigorously shaken, and then allowed to equilibrate for at least $48 \mathrm{~h}$, at $23{ }^{\circ} \mathrm{C}$. Tie-line determination was performed using the methodology described by Anita Kaul. ${ }^{11}$ Salt concentration was measured in both phases by electrical conductivity (WTW LF538 Conductivity Meter), at $23{ }^{\circ} \mathrm{C}$. For each salt, a calibration curve was obtained after measuring the electrical conductivity of several stock solutions with known salt concentrations within the range (0.01 to 0.2 ) $\%(\mathrm{w} / \mathrm{w})$. Polymer interference in the electrical conductivity measurements was tested for the range (0.01 to 0.5$) \%(w / w)$, and no interferences were observed. Average errors in salt concentration, calculated using the calibration lines, were below $2 \%$ for all salts used. Three samples from the top and bottom phases were withdrawn and conveniently diluted, and the electrical conductivity was measured. Final salt concentration for each phase was obtained from the average of the three measurements (standard deviations less than $0.2 \%$ ), after convenient correction with the dilution factor. Polymer concentration in the top phase was assessed gravimetrically after lyophilization: three samples of the top phase were taken, diluted with water (1/5), and placed in the freezer at $-18{ }^{\circ} \mathrm{C}$ for $24 \mathrm{~h}$. After being frozen, the samples were freeze-dried, and the average dry weight was determined (standard deviation less than $0.15 \%)$. The final polymer concentration for the top phase was calculated by subtraction of the salt concentration from the average dry weight. The polymer concentration in the bottom phase was obtained using the salt concentration previously determined and the Merchuk equation.

\section{Results and Discussion}

The experimental binodal curves for the six UCON-phosphate salt ATPSs were successfully adjusted to the Merchuk equation. The values obtained for the parameters $a, b$, and $c$ in eq 1 are
Table 2. Tie-Line Compositions (In Mass Fraction) Determined for the Feed, Top, and Bottom Phases and the Corresponding Tie-Line Length and Slope

\begin{tabular}{|c|c|c|c|c|c|c|c|}
\hline \multicolumn{2}{|c|}{ feed } & \multicolumn{2}{|c|}{ top phase } & \multicolumn{2}{|c|}{ bottom phase } & \multirow[b]{2}{*}{ STL } & \multirow[b]{2}{*}{ TLL } \\
\hline salt & polymer & salt & polymer & salt & polymer & & \\
\hline \multicolumn{8}{|c|}{$\mathrm{UCON}-\mathrm{K}_{2} \mathrm{HPO}_{4}$} \\
\hline 0.0380 & 0.1802 & 0.025 & 0.237 & 0.073 & 0.011 & -4.81 & 0.230 \\
\hline 0.0400 & 0.1998 & 0.020 & 0.286 & 0.083 & 0.003 & -4.54 & 0.290 \\
\hline 0.0420 & 0.2200 & 0.017 & 0.324 & 0.093 & 0.001 & -4.22 & 0.332 \\
\hline \multicolumn{8}{|c|}{$\mathrm{UCON}-\mathrm{KPB}^{a}$} \\
\hline 0.0530 & 0.1301 & 0.029 & 0.227 & 0.080 & 0.017 & -4.14 & 0.215 \\
\hline 0.0570 & 0.140 & 0.024 & 0.267 & 0.091 & 0.006 & -3 . & 0.269 \\
\hline 0.0610 & 0.1502 & 0.020 & 0.299 & 0.101 & 0.002 & -3.70 & 0.308 \\
\hline \multicolumn{8}{|c|}{$\mathrm{UCON}-\mathrm{KH}_{2} \mathrm{PO}_{4}$} \\
\hline 0.0700 & 0.1500 & 0.040 & 0.264 & 0.106 & 0.015 & -3.74 & 0.258 \\
\hline 0.0760 & 0.1720 & 0.033 & 0.317 & 0.126 & 0.003 & -3 & 0.328 \\
\hline 0.0850 & 0.1899 & 0.028 & 0.369 & 0.146 & 0.0003 & -3.12 & 0.387 \\
\hline \multicolumn{8}{|c|}{$\mathrm{UCON}-\mathrm{Na}_{2} \mathrm{HPO}_{4}$} \\
\hline 0.0350 & 0.1491 & 0.019 & & 0.059 & 0.014 & -5.56 & 0.227 \\
\hline 0.0390 & & 0.014 & & 0.068 & & & 0.283 \\
\hline 0.0430 & 0.1730 & 0.012 & 0.315 & 0.078 & 0.001 & -4.78 & 0.321 \\
\hline \multicolumn{8}{|c|}{$\mathrm{UCON}-\mathrm{NaPB}^{b}$} \\
\hline 0.0391 & 0.1597 & 0.018 & & 0.068 & 0.009 & -5.16 & 0.259 \\
\hline 0.0430 & & 0.015 & 0.29 & 0.078 & 0.0 & -4 & 0.302 \\
\hline 0.0470 & 0.1859 & 0.012 & 0.336 & 0.087 & 0.0004 & -4.50 & 0.344 \\
\hline \multicolumn{8}{|c|}{$\mathrm{UCON}-\mathrm{NaH}_{2} \mathrm{PO}_{4}$} \\
\hline 0.0650 & 0.1600 & 0.032 & 0.292 & 0.103 & 0.005 & -4.04 & 0.295 \\
\hline 0.0699 & & 0.028 & 0.340 & 0.119 & 0.001 & -3.72 & 0.351 \\
\hline 0.0800 & 0.2000 & 0.023 & 0.392 & 0.140 & 0.00003 & -3.36 & 0.409 \\
\hline
\end{tabular}

${ }^{a} \mathrm{KPB}$ : Potassium phosphate buffer. ${ }^{b} \mathrm{NaPB}$ : Sodium phosphate buffer.

shown in Table 1. The coefficients of determination $\left(r^{2}\right)$ are, in all cases, greater than 0.999 (see Table 1).

The end of the tie-lines for the six UCON-phosphate salt ATPS are given in Table 2. Due to the low concentration of polymer in the bottom phase and the errors associated to salt quantification by electrical conductivity, the values obtained for UCON concentration by lyophilization were not satisfactory in this phase. For this reason, the UCON concentration in bottom phases was calculated using the Merchuk equation. The tieline lengths (TLL) were calculated using the equation:

$$
\mathrm{TLL}=\sqrt{\left(X_{\text {top }}-X_{\text {bottom }}\right)^{2}+\left(Y_{\text {top }}-Y_{\text {bottom }}\right)^{2}}
$$

The slopes of the tie-lines (STL) were obtained from linear regression of the top, bottom, and feed compositions of the tielines. The corresponding values for the TLL and STL are presented in Table 2.

The complete phase diagrams obtained for the six ATPSs are presented in Figures 1 to 3. The STL obtained (Table 2) cannot be considered constant within each ATPS. The experimental errors for each STL are far below the variations of the different STL. The absolute value of the STL decreases as the TLL increases (Table 2) in all the six ATPSs studied. No results were found in the literature for $\operatorname{UCON}\left(M_{W}=3900\right)$ - phosphate 


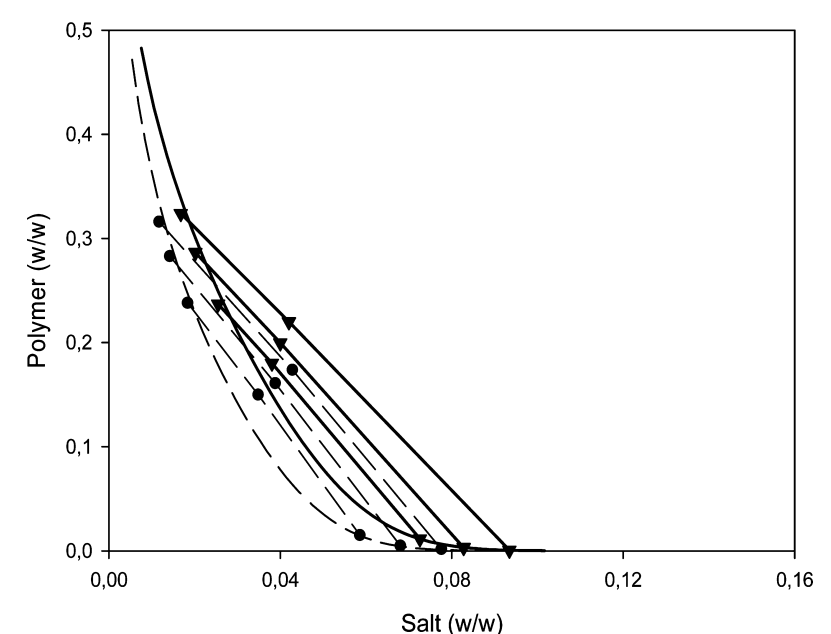

Figure 1. Binodal curve and tie-lines obtained at $23{ }^{\circ} \mathrm{C}$ for the systems: $\mathrm{UCON}-\mathrm{K}_{2} \mathrm{HPO}_{4}\left(-\boldsymbol{\nabla}\right.$-) and $\mathrm{UCON}-\mathrm{Na}_{2} \mathrm{HPO}_{4}$ (- - - -).

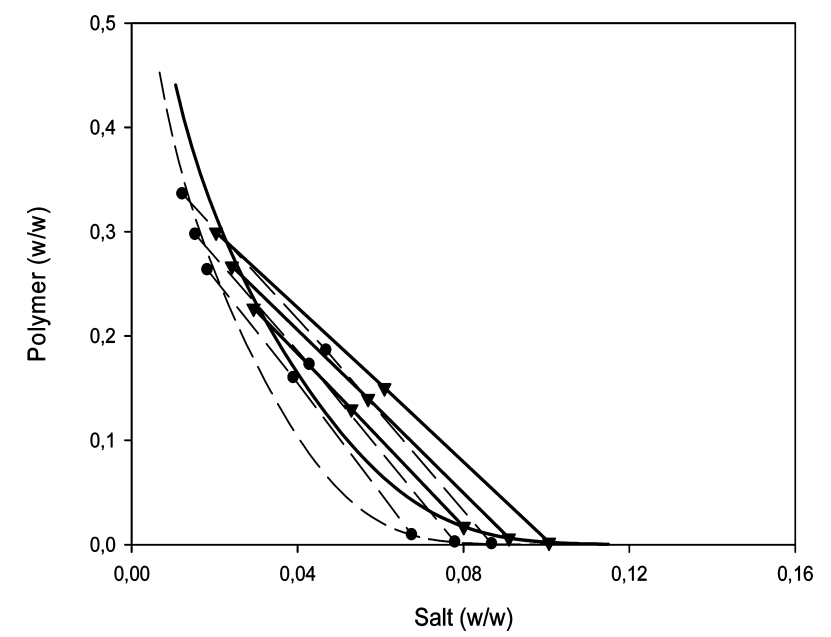

Figure 2. Binodal curve and tie-lines obtained at $23{ }^{\circ} \mathrm{C}$ for the systems: UCON-potassium phosphate buffer $\mathrm{pH}=7$ (-- -) and UCON-sodium phosphate buffer $\mathrm{pH}=7$ (- - - -).

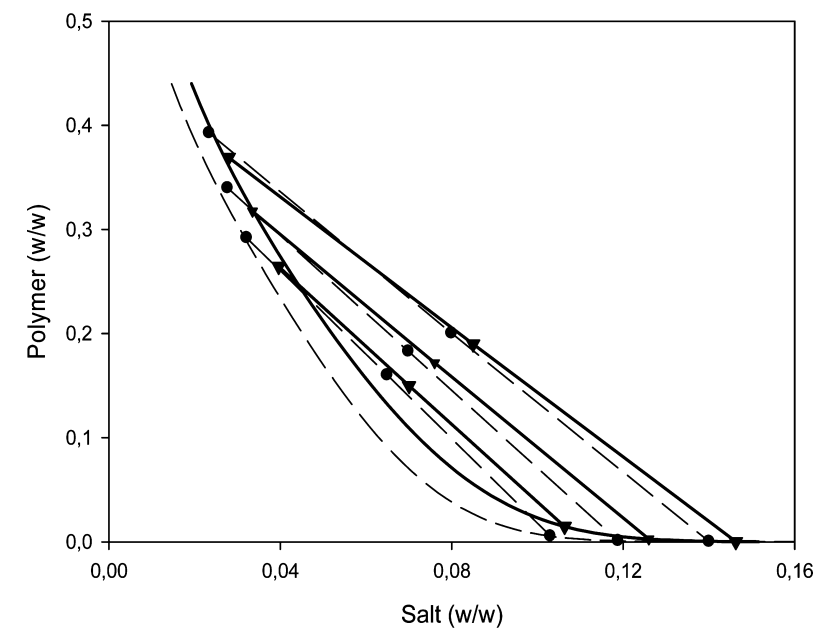

Figure 3. Binodal curve and tie-lines obtained at $23{ }^{\circ} \mathrm{C}$ for the systems: $\mathrm{UCON}-\mathrm{KH}_{2} \mathrm{PO}_{4}(-\boldsymbol{\nabla}-)$ and $\mathrm{UCON}-\mathrm{NaH}_{2} \mathrm{PO}_{4}(--\bullet-$ - $)$.

salt ATPSs at $23{ }^{\circ} \mathrm{C}$. Nevertheless, our results are in agreement with those obtained by $\mathrm{Li}$ et al. ${ }^{12}$ using $\operatorname{UCON}\left(\mathrm{M}_{\mathrm{W}}=\right.$ 4650)-potassium phosphate salts at $25^{\circ} \mathrm{C}$ : the STL values for $\mathrm{UCON}-\mathrm{KH}_{2} \mathrm{PO}_{4}$ and $\mathrm{UCON}-$ potassium phosphate buffer ATPSs are similar, but slight variations are observed for the system $\mathrm{UCON}-\mathrm{K}_{2} \mathrm{HPO}_{4}$. These variations may be caused by

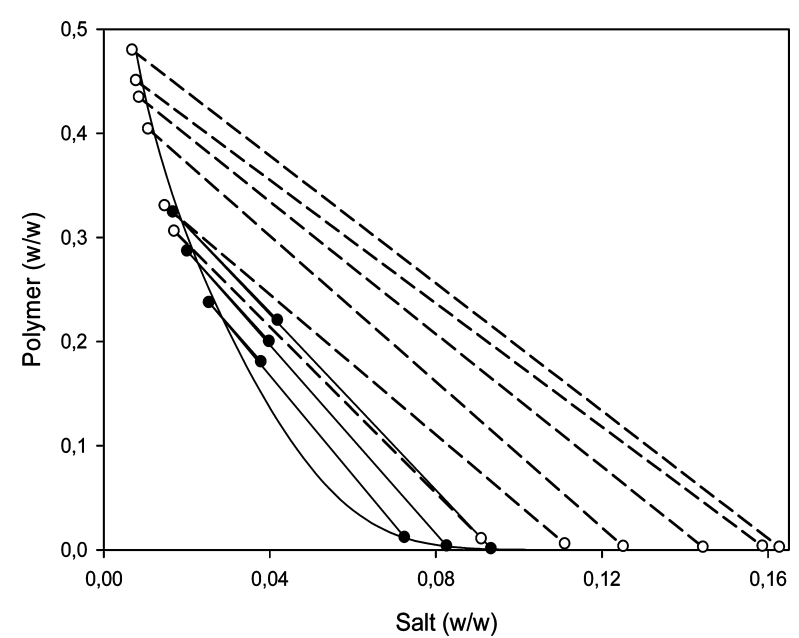

Figure 4. Comparison of the obtained phase diagram for $\operatorname{UCON}\left(M_{\mathrm{w}}=\right.$ $3900)-\mathrm{K}_{2} \mathrm{HPO}_{4}$ at $23{ }^{\circ} \mathrm{C} \mathrm{(- \nabla -)}$ with that reported by $\mathrm{Li}$ et al. $(1998)^{11}$ for $\operatorname{UCON}\left(M_{\mathrm{w}}=4650\right)-\mathrm{K}_{2} \mathrm{HPO}_{4}$ at $25^{\circ} \mathrm{C}(--\mathrm{O}--)$.

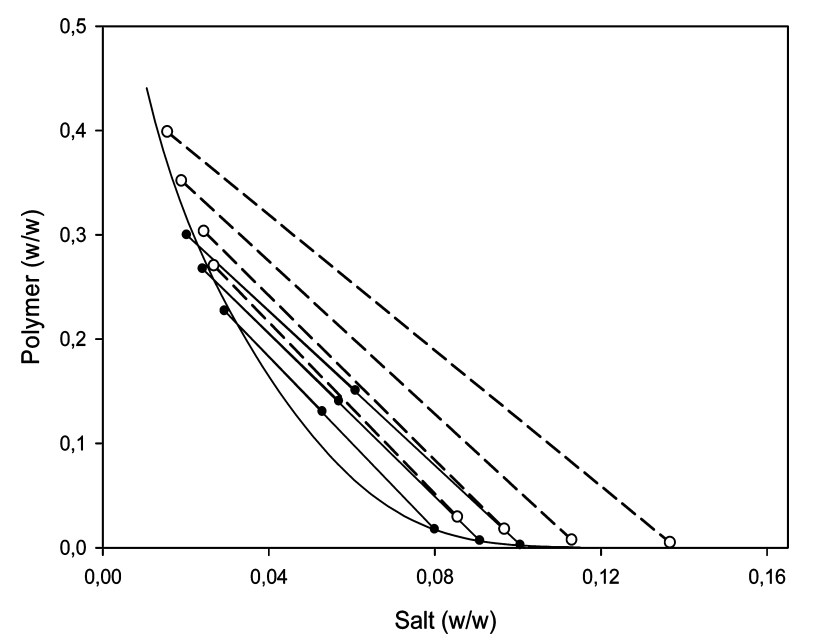

Figure 5. Comparison of the obtained phase diagram for $\operatorname{UCON}\left(M_{\mathrm{w}}=\right.$ $3900)$ - potassium phosphate buffer $\mathrm{pH}=7$ at $23^{\circ} \mathrm{C}(-\nabla-)$ with that reported by Li et al. ${ }^{11}$ for UCON $\left(M_{\mathrm{w}}=4650\right)$ - potassium phosphate buffer $\mathrm{pH}=$ 6.8 at $25^{\circ} \mathrm{C}\left(--\mathrm{O}_{--}\right)$.

the small differences between the molecular weights or the end groups of UCON used. Comparison of the obtained phase diagrams with those reported by $\mathrm{Li}$ et al. for the systems $\mathrm{UCON}-\mathrm{K}_{2} \mathrm{HPO}_{4}$ and $\mathrm{UCON}-$ potassium phosphate buffer are shown in Figures 4 and 5, respectively.

Among the salts studied, the most effective salt for ATPS formation is $\mathrm{Na}_{2} \mathrm{HPO}_{4}$, while $\mathrm{KH}_{2} \mathrm{PO}_{4}$ provides the smallest heterogeneous region. It is evident for both cations $\left(\mathrm{Na}^{+}\right.$and $\left.\mathrm{K}^{+}\right)$that the higher the valence of the anion $\left(\mathrm{HPO}_{4}{ }^{2-}>\right.$ $\mathrm{H}_{2} \mathrm{PO}_{4}{ }^{-}$), the lower the concentration needed to form a biphasic system and the higher the STL values obtained. An analogous behavior was previously reported ${ }^{13}$ for PEG6000 and PEG1000 with $\mathrm{Na}_{2} \mathrm{HPO}_{4}$ and $\mathrm{NaH}_{2} \mathrm{PO}_{4}$. The proximity between the $\mathrm{HPO}_{4}{ }^{2-}$ binodal and the buffer binodal was expected due to the mole ratio $(x)$ of $\mathrm{HPO}_{4}{ }^{2-}$ to $\mathrm{H}_{2} \mathrm{PO}_{4}{ }^{-}$salt used in the buffers ( $x=1.6$ for potassium phosphate buffer and $x=2.9$ for sodium phosphate buffer). The tendency found for the size of the heterogeneous region, $\mathrm{HPO}_{4}{ }^{2-}>$ buffer $>\mathrm{H}_{2} \mathrm{PO}_{4}{ }^{-}$, is in agreement with previous results ${ }^{12}$ and allows one to relate the $\mathrm{pH}$ value of the salt used and the size of the heterogeneous region in the phase diagram. Thus, the heterogeneous region increases with the $\mathrm{pH}$ of the salt solution. This fact is also supported by the variation observed in the binodal curve when 
comparing the systems: UCON (MW = 3900)-potassium buffer $\mathrm{pH}=7$ and UCON (MW = 4650)-potassium buffer $\mathrm{pH}=6.8 .^{12}$ The latter provides a smaller heterogeneous region in the phase diagram (Figure 5).

A comparison of the influence of the cations deserves further attention. $\mathrm{Na}^{+}$is clearly more effective than $\mathrm{K}^{+}$in ATPS formation, and the biphasic regions obtained with sodium salts are larger than the corresponding potassium salts in all cases. The STL values are also higher for the ATPSs composed by sodium salts (Table 2). An equivalent effect was previously reported for other types of polymer-salt ATPSs on the size of the heterogeneous region, using sodium and potassium salts. ${ }^{14,15}$ According to the Hofmeister series, ${ }^{16}$ the salting-out effect of $\mathrm{Na}^{+}$is greater than $\mathrm{K}^{+}$, and consequently $\mathrm{Na}^{+}$is expected to present more ability to form ATPS than $\mathrm{K}^{+}$. Another way to explain the differences observed for the cations is the analysis of the energy of hydration $\left(\Delta G_{\mathrm{hyd}}\right):-295 \mathrm{~kJ} \cdot \mathrm{mol}^{-1}$ for $\mathrm{K}^{+}$ and $-365 \mathrm{~kJ} \cdot \mathrm{mol}^{-1}$ for $\mathrm{Na}^{+}$. ${ }^{17}$ This means that $\mathrm{Na}^{+}$has a larger hydration shell, thus reducing the amount of water available to hydrate the polymer and therefore providing the salting-out of the polymer. The same explanation can be used for the anion effect in ATPS formation: monovalent anions have $\Delta G_{\text {hyd }}$ values less negative than their corresponding divalent anions. ${ }^{17}$ Another fact that can also be related to the $\Delta G_{\text {hyd }}$ values of the ions is the STL (Table 2): more negative values of $\Delta G_{\text {hyd }}$ result in higher STL values, which is in agreement with the literature. ${ }^{18}$

\section{Conclusions}

Six new phase diagrams for UCON-phosphate salt ATPSs at $23{ }^{\circ} \mathrm{C}$ were presented. Among the salts studied, $\mathrm{Na}_{2} \mathrm{HPO}_{4}$ proved to be the most effective for ATPS formation, while $\mathrm{KH}_{2} \mathrm{PO}_{4}$ requires the higher concentration to achieve phase splitting. The effect of the anion and the cation in ATPS formation was discussed. The energy of hydration of the ions can be used to explain the ability to form ATPS: more negative values of $\Delta G_{\text {hyd }}$ provide larger heterogeneous regions in the phase diagrams. $\Delta G_{\text {hyd }}$ is also associated with the STL value: higher STL values are obtained for the systems with more negative values of $\Delta G_{\text {hyd }}$. According to the results, a relation between the $\mathrm{pH}$ value of the salt and the size of the heterogeneous region was established: the lower the $\mathrm{pH}$ of the salt the smaller the heterogeneous region obtained.

\section{Literature Cited}

(1) Liu, C.; Kamei, D.; King, J.; Wang, D.; Blankschtein, D. Separation of proteins and viruses using two-phase aqueous micellar systems. J. Chromatogr. B 1998, 711, 127-138.

(2) Hamamoto, R.; Kamihira, M.; Iijima, S. Specific separation of animal cells using aqueous two-phase systems. J. Ferment. Bioeng. 1996, 82, $73-76$.
(3) Rito-Palomares, M.; Dale, C.; Lyddiatt, A. Aqueous two-phase fractionation of biological suspensions for protein recovery from bovine blood. Biotechnol. Tech. 1998, 12, 711-714.

(4) Kumar, A.; Srivastava, A.; Galaev, I.; Mattiasson, B. Smart polymers: physical forms and bioengineering applications. Prog. Polym. Sci. 2007, 32, 1205-1237.

(5) Wang, W.; Wan, J.; Ning, B.; Xia, J.; Cao, X. Preparation of a novel light-sensitive copolymer and its application in recycling aqueous twophase systems. J. Chromatogr. A 2008, 1205, 171-176.

(6) FanQi, K.; Xuejun, C.; Jinan, X.; Hur, B. Synthesis and applications of a light-sensitive polymer forming aqueous two-phase systems. J. Ind. Eng. Chem. 2007, 13, 424-428.

(7) Persson, J.; Kual, A.; Tjerneld, F. Polymer recycling in aqueous twophase extractions using thermoseparating ethylene oxide-propylene oxide copolymers. J. Chromatogr. B 2000, 743, 115-126.

(8) Persson, J.; Johansson, H.; Tjerneld, F. Purification of protein and recycling of polymers in a new aqueous two-phase system using two thermoseparating polymers. J. Chromatogr. A 1999, 864, 31-48.

(9) Pereira, M.; Wu, Y.; Madeira, P.; Venâncio, A.; Macedo, E.; Teixeira, J. Liquid-liquid equilibrium phase diagrams of new aqueous two-phase systems: Ucon 50-HB5100 + Ammonium sulphate + water, Ucon 50 -HB5100 + Poly(vinyl alcohol) + water, Ucon 50-HB5100 + Hydroxypropyl starch + water, and Poly(ethylene glycol) $8000+$ Poly(vinyl alcohol) + water. J. Chem. Eng. Data 2004, 49, 43-47.

(10) Merchuk, J.; Andrews, B.; Asenjo, J. Aqueous two-phase systems for protein separation-studies on phase inversion. J. Chromatogr. B 1998, 711, 285-293.

(11) Kaul, A. The Phase Diagram. In Aqueous Two-phase Systems, Methods and Protocols; Hatti-Kaul, R., Ed.; Humana Press: NJ, 2000; Chapter 2, p 19.

(12) Li, M.; Wang, Y.; Zhu, Z. Liquid-liquid equilibria for random copolymer of ethylene oxide + propylene oxide + salt + water. J. Chem. Eng. Data 1998, 43, 93-96.

(13) Zafarani-Moattar, M.; Sadeghi, R. Liquid-liquid equilibria of aqueous two-phase systems containing polyethylene glycol and sodium dihydrogen phosphate or disodium hydrogen phosphate-Experiment and correction. Fluid Phase Equilib. 2001, 181, 95-112.

(14) Rogers, R.; Bauer, C. Partitioning behaviour of group 1 and 2 cations in poly(ethylene glycol)-based aqueous biphasic systems. J. Chromatogr. B: Biomed. Appl. 1996, 680, 237-241.

(15) Shibukawa, M.; Matsuura, K.; Shinozuka, Y.; Mizuno, S.; Oguma, $\mathrm{K}$. Effects of phase-forming cations and anions on the partition of ionic solutes in aqueous polyethylene glycol-inorganic salt two-phase system. Anal. Sci. 2000, 16, 1039-1044.

(16) Kunz, W.; Henle, J.; Ninham, B. 'Zur lehre von der wirkung ser salze' (about the science of the effect of salts): Franz Hofmeister's historical papers. Curr. Opin. Colloid Interface Sci. 2004, 9, 19-37.

(17) Marcus, Y. Thermodynamics of salvation of ions, Part 5.-Gibbs free energy of hydration at 298,15 K. J. Chem. Soc. Faraday Trans. 1991, 87, 2995-2999.

(18) Zafarani-Moattar, M.; Hamzehzadeh, S. Liquid-liquid equilibria of aqueous two-phase systems containing 1-butyl-3-methylimidazolium bromide and potassium phosphate or dipotassium hydrogen phosphate at 298.15 K. J. Chem. Eng. Data 2007, 52, 1686-1692.

Received for review July 23, 2009. Accepted November 27, 2009. Financial support for this work was in part provided by Fundação para a Ciência e a Tecnologia (FCT, Portugal) and by LSRE financing by FEDER/POCI/2010, for which the authors are thankful. Oscar Rodríguez acknowledges financial support of Programme Ciência 2007 (FCT). Sara Silvério acknowledges her Ph.D. grant of FCT (SFRH/BD/43439/2008).

JE900628M 